\title{
Towards a More Natural Governance of Earth's Biodiversity and Resources
}

\author{
D.W. Macdonald ${ }^{\mathrm{a}, \#}$, D.D.P. Johnson ${ }^{\mathrm{b}}$, and H. Whitehouse ${ }^{\mathrm{c}}$ \\ ${ }^{a}$ Wildlife Conservation Research Unit, Department of Zoology, University of Oxford, The Recanati-Kaplan Centre, Oxford, UK \\ ${ }^{b}$ Department of Politics and International Relations, University of Oxford, Oxford, UK \\ 'School of Anthropology and Museum Ethnography, University of Oxford, Oxford, UK
}

\#Corresponding author. E-mail: david.macdonald@zoo.ox.ac.uk

\begin{abstract}
Humans, like other animals, have aptitudes and limitations shaped by natural selection; knowledge of these-along with that of how mammals, including people, form societies and cooperate - can be fruitfully applied to the challenge of biodiversity conservation. Here, we outline the natural principles that might help conservationists (and indeed any other group concerned with political problems) get the best outcomes by aligning efforts with the grain of nature, rather than against it; we call this approach 'Natural Governance'. We illustrate the value of this perspective with reference to two aspects of conservation strategy - rethinking the spatial scales at which it is effective to plan conservation and energising human society to care enough to enable it. A Natural Governance approach stands on three critical pillars: (1) ecology (the dynamic balance between organisms and their environment), (2) cooperation (adaptations to act collectively even where this incurs short-term costs to self-interest), and (3) cultural systems (how these adaptations are manifested and vary across societies). It is commonly assumed that human society stems purely from political or socially-constructed influences. The biological perspective does not say that these influences are unimportant, but it reveals viewing humanity out of the evolutionary context to be a cripplingly narrow picture.
\end{abstract}

Keywords: natural governance, ecology, cooperation, cultural systems

\section{INTRODUCTION}

"In my view you cannot have a serious discussion about the nature and future of humankind without beginning with our fellow animals".

- Yuval Noah Harari, Homo Deus (2016)

Planning a future for the human enterprise that ignores our biological nature would be as foolhardy as trying to live on less than $1500 \mathrm{kcal}$ a day or run a marathon in less than 2 hours at $5000 \mathrm{~m}$ above msl. Like all species we have evolved

\begin{tabular}{|l|l|}
\hline \multicolumn{2}{|c|}{ Access this article online } \\
\hline Quick Response Code: & Website: \\
\hline & www.conservationandsociety.org \\
\cline { 2 - 3 } & \\
\hline
\end{tabular}

remarkable adaptations, and also design limitations that we ignore at our peril. This simple thought that we should be wary of "mismatches" between our longstanding design and our contemporary habits has been fruitfully highlighted in spheres as diverse as medicine (Gluckman and Hanson 2006), economics (Kahneman 2011), and psychology (Giphart and Van Vugt 2018). For those who deny the fact of evolution, apparently including 39\% of Americans (Miller et al. 2006), it may be an inconvenient truth that we are mammals at all. Nevertheless, knowledge of how mammals, including people, tend to form societies and cooperate has barely been tapped by those thinking about how the human enterprise might best govern itself. Rather than imposing abstract ideas from above (which human nature may or may not align with), we propose developing bottom up strategies, in which alignment with or recognition of human nature is the guiding design principle. So far as we know, it has also not been applied to the challenge of biodiversity conservation - noteworthy in itself, considering the strong consensus on how to use biological principles to solve biological problems. Politics and economics are failing

Copyright: (C) Macdonald et al. 2018. This is an open access article distributed under the terms of the Creative Commons Attribution License, which permits unrestricted use and distribution of the article, provided the original work is cited. Published by Wolters Kluwer - Medknow, Mumbai | Managed by the Ashoka Trust for Research in Ecology and the Environment (ATREE), Bangalore. For reprints contact: reprints@medknow.com 
to solve major global challenges on their own; we argue that a large part of the reason for this failure is that people have not thought hard enough about the natural inclinations of the would-be conservers - us. In our view, it is time to take human nature seriously (without getting mired in nature/nurture debates), and identify ways to use this rapidly expanding body of scientific knowledge to our advantage.

Here, we outline the natural principles that might help conservationists (and indeed any other group concerned with political problems) get the best outcomes by aligning efforts with the grain of nature, rather than against it; we call this approach 'Natural Governance'. By this, as will become clear by example, we do not mean governance according to a set of criteria that are somehow 'natural'; we mean governance being mindful of, and inquisitive about, the broadly biological forces that have shaped us and to which we are, in a Darwinian sense, adapted ${ }^{1}$. Just as the behavioural sciences have radically improved economics and public policy, recognising the role of human behaviour in resource governance can make it more "natural" and more successful as a result. We illustrate the value of this perspective with reference to two aspects of conservation strategy - rethinking the spatial scales at which it is effective to plan conservation, and energising human society to care enough to enable it - even when, or especially when, it lies beyond our own backyard. Both draw on the wealth of scientific knowledge on how animal, including human, behaviour evolved, and particularly how societal relationships are formed and maintained in relation to life-sustaining resources.

A Natural Governance approach stands on three critical pillars: (1) ecology (the dynamic balance between organisms and their environment), (2) cooperation (adaptations to act collectively even where this incurs short-term costs to selfinterest), and (3) cultural systems (how these adaptations are manifested and vary across societies). Our perspective on mammalian (or any other) societies starts with the obvious point that they are emergent properties of ecology and evolution-including to an important extent among humans, where it is commonly assumed that society stems purely from political or socially-constructed influences. The biological perspective does not say that these influences are unimportant, but it reveals viewing humanity out of the evolutionary context to be a cripplingly narrow picture.

\section{ECOLOGICAL FOUNDATIONS: THE SHAPE OF CONSERVATION TO COME}

In the past, the tendency was to assume that if animal societies are to get bigger, they simply need to expand their territory size to support their growing numbers. But it turns out this intuitive relationship is often violated. Hans Kruuk (1975) observed a curious puzzle in nature, in that some carnivore species lived in large groups, yet never cooperated with each

1 Natural Governance as thus explained is therefore entirely different to other usages that juxtapose the words nature and governance in the context of resource management-such terms are well explained by, e.g., Agrawal and Lemos 2007. other. Building on this, Macdonald (1983) hypothesised that some societies became large not because of the benefits of group life, but because of the constraints of their ecology, and in particular the energetic benefits of sharing space. The idea is that groups larger than necessary for reproduction (that is, larger that the minimal reproductive unit) may develop under a certain, common scenario - where resources are dispersed in space and time such that the smallest economically defensible territory for a pair (or whatever is the minimal reproductive unit) is rich enough to also sustain additional animals. Whether these additional animals opt to share, or are permitted to share, the territory will depend on their capacity to tolerate variation in these surplus resources (and thus the prevailing level of "food security" - these and related terms are defined in Carr and Macdonald 1986). This "Resource Dispersion Hypothesis" (RDH) thus identifies a mechanism to explain how spatial groups can form even where cooperation or other benefits of group living are absent (as well as helping to explain the use of space by animals that are social). In a recent review, Macdonald and Johnson (2015) report that RDH has now been invoked in 65 empirical studies of a diversity of non-human and human societies. Let us lay out the original case study before expanding on how it generalises to, in fact, all life on Earth.

The seminal model that inspired Kruuk's original observation arose from studies of the European badger Meles meles near Oxford (Kruuk 1978; Macdonald and Newman 2017). Badgers eat earthworms that surface, and thus become available only where the microclimate is right, and particularly in lee of the wind. Thus, a single badger, or a breeding pair, living on an imagined hill, might find food on the north, south, east or west slope depending of the direction of the wind on a given night. If they are to eat irrespective of wind direction, this basic social unit of badgers must configure a territory that encompasses all sides of the hill. But then on any one night on the bountiful side of the hill and within the smallest territory needed over many nights for just one pair, there will be an abundance of available worms that could - with minimal costs to tolerating cohabitation - accommodate a whole group of badgers. The principle is clear-indivisibility of the smallest economically viable constellation of resources, combined with the shareability of the resources therein, facilitates (without necessarily encouraging) group formation without any reference to cooperation (a phenomenon that applies in principle to any species and any resource, confirmed mathematically, inter alia, by Blackwell [1990] and as explored in detail by Macdonald and Johnson [2015]). Such social agglomerations may have set the scene for the later evolution of cooperation, but they did not require or rely on it. Hence, ecology alone can explain the membership of some social groups - irrespective of behavioural cooperation. Of course, in reality, we often observe both ecological and social factors shaping the societies of group-living species - the two factors not being mutually exclusive. However, the power of the ecological side of the coin had not been fully recognised without the RDH. Among its many interesting extensions, there may be a subsequent incentive for expansionism beyond 
the smallest defendable spatial unit to a larger one supporting a larger and bountifully cooperative group (Kruuk and Macdonald 1985), because, for example, group members can share the costs of rearing young, dealing with predators or of territorial patrols. In this way, environments conducive to $\mathrm{RDH}$ living may in fact have formed the basis for the evolution of society, in a kind of ecological-social virtuous circle. Note, however, that ecology holds an intrinsic leverage-if space cannot be shared, groups cannot form in the first place.

From this starting point in mammalian ecology, the important point made by Macdonald and Johnson (2015) was that the principle of hedging bets over food security in $\mathrm{RDH}$ (first expressed in statistical terms by Carr and Macdonald in 1986) could be applied to humans as well as other animals. This is applicable not only, obviously, to small-scale human societies, but also, less obviously, to many aspects of the contemporary human enterprise. In one remarkable example, the smallest viable home range for one boat of lobster fishermen in Maine is indivisible (because lobster movements across the seasons mean one must fish over a wide area) and yet the same space supports a whole fleet of boats, because wherever they become concentrated within this expanse of water, the lobster are abundant and there are plenty to go around. If one divided the water into territories, individuals would occasionally have a flash super-abundance, which would be more than they could deal with and no one would have a reliable supply over time. The much better solution is to share the space and the windfalls. Similarly, while the smallest operational unit for some Polynesian societies was an indivisible set of islands which could support many families, each island produced something unique that the others needed and there was enough of each resource to share. Hence, all islanders needed all the islands and thus they could not be (and did not need to be) carved up into exclusive slices of a pie. Such reliance on shared resources has been a feature of human economies for centuries. By extension, for example, the modern international economy supports populations in Chicago and Harbin that share resources through trade, even though they occupy distant geographies.

A striking regularity in the organisation of organisms across environmental contexts should not be a surprise; Nobel Laureate Elinor Ostrom noticed that the most spatiotemporally variable resources were precisely the ones that represented commonpool resources - resources that must be shared and are rendered useless if carved out as private slices of pie (Ostrom 1990). Only resources that are reliably found in the same place can be divided up into exclusive territories. Relaxing the assumption of resources being anchored to geography (their accessibility can be patchy in terms of time as well as space), the RDH and the principle of indivisibility-and-shareability and the associated bet hedging reveals that the fundamental consequences of patchiness are at work in everything from the Black Scholes mathematical model of financial markets to Maasai pastoral migrations (Western et al. submitted 2018a). Resources rarely come reliably and continuously anywhere in nature, and the challenge for biological organisms is to smooth out the input of energy from the environment so they can sustain life over time - even during periods of shortage. The question is how this fundamental feature of life on a patchwork planet has a bearing on conservation. How do we recognise and preserve the whole pattern of the quilt rather than conserving a pile of independent patches, each of which on its own may be useless?

\section{CONSERVATION IMPLICATIONS: SIZES MATTER}

Consider Dynamite. He was a lion that Oxford's Wildlife Conservation Research Unit (WildCRU) had been tracking in Zimbabwe's Hwange National Park, an area half the size of Wales and which turned out to be not big enough for Dynamite. The researchers' efforts were originally focused on this 14,600 sq. $\mathrm{km}$ protected area and safeguarding the lion population therein. With the introduction of satellite tracking data, however, we were able to discover that one day Dynamite took off, travelling over $150 \mathrm{~km}$ along a convoluted route that took him beyond the park, and indeed beyond Zimbabwe, into Zambia. Dynamite waves the flag for many lions (Elliot et al. 2014) whose movements have now been logged in that landscape, revealing that the smallest area necessary to protect their population and the ecological processes of which this area is a part embraces a constellation of protected areas and variously threatened corridors between them-spanning five countries in the Kavango-Zambezi Trans-frontier Conservation Area (Cushman et al. 2018). The problem is magnified with wide-ranging elephants, seasonal ungulate movements, or migrating birds (for the latter of which we must protect spaces in different hemispheres of the globe). Just as a farmland conservationist would consider the minimum functional unit for planning as the watershed rather than the hedgerow, field or farm (Macdonald and Feber 2015), Dynamite teaches us that large mammal conservationists must similarly strive to identify the minimal functional area required to sustain ecological processes; this perspective also reveals that in many cases, existing political units such as nation states (especially those cookie cut simply by colonial whim) are an arbitrary inconvenience - sovereign only in making decisions within their borders and unable to ensure conservation security beyond them. For large mammals, wide-ranging birds, ecosystems, and the global climate, political borders become a wall to common sense. The lion does not see our imaginary boundaries, yet we humans literally legislate along a line in the sand.

While conservation might aspire to nurture units of space as large as possible, this is of course increasingly constrained in fragmented environments and where ecosystems straddle national borders. An RDH perspective allows us to shift focus and ask what units are large enough (i.e., are as small as necessary) — where the definition of necessity might be, analogous to $\mathrm{RDH}$, the smallest area that enables critical ecological processes of that ecosystem or community to function, and yet within which multiple individuals (and indeed multiple species) can share. This concept might be de facto embodied in, for example, the Convention of Migratory Species that recognises that protecting the Arctic 
tern in its northern breeding grounds is not much use unless it is also protected in its Antarctic non-breeding grounds, or indeed that it has a right of passage between them (recognition directly relevant to Dynamo the lion, Trouwborst et al. 2017; Hodgetts et al. 2018). It is also similar to the conservation concept of metapopulation management pioneered for African wild dogs (Davies-Mostert et al. 2009), which extends the notion of a population that functions fully only by accommodating the blinking in and out of existence of a constellation of component parts. The RDH supports a critical pillar of the Natural Governance framework, helping to justify and calculate efforts to conserve a species' ecological network as well as the animals themselves. Imagine, for example, contours of functionality that encompass the dispersal movements and protected areas that unite the Kavango-Zambezi lion population that spans parts of Zimbabwe, Botswana, Namibia, Zambia, and Angola; also imagine congruence between them and the migratory zebra and elephants of the region, and how a functional unit, indeed the smallest fully functional unit that protected them, would potentially also protect all the charismatic carnivores of the region along with their prey and everything that hops, flaps, slithers, and crawls in that region (the notion of shared conservation 'umbrellaness' was elaborated for felids and primates by Macdonald et al. 2012 and the choice of ambassador species is tackled in Macdonald et al. 2017).

Having defined operational units for conservation, notwithstanding the unhelpful arbitrariness of nation states (a polity one might futuristically imagine becoming less distinct in the globalised and internet era, at least in the conservation domain), we turn again to fundamental biological principles for inspiration on how to best manage them.

\section{COLLECTIVE ACTION: BRINGING OUT THE BEST IN US}

These problems fall into the sphere of collective action/ non-action, which has been richly studied in an extensive literature (e.g., Ostrom 1990; Agrawal and Lemos 2007). Nonetheless, the massive scales and multiple sovereign (and often competing) states pose severe challenges (e.g., Stein 1990). If killing our borderless ecosystems by a thousand cuts is to be avoided, we will require unprecedented levels of coordination and cooperation; as a super-problem, it requires super-normal levels of cooperation and collective action to solve it. While states may be inherently constrained in their ability to align interests (it is possible but hard), as human beings we at least have adaptations to align our own interests with others. It is something that natural selection made us good at in order to survive as a social species in a challenging environment. Curry et al. (submitted) conclude from a review of the literature that seven evolutionary mechanisms ${ }^{2}$ and their

2 Evolutionary theory has provided specific explanations for seven dispositions: why people [1] care for their families, [2] help their groups, [3] reciprocate favours (and punish cheats), [4] perform heroic acts of altruism, [5] defer to authority, [6] act fairly, and [7] respect others' property. resulting cooperative adaptations in humans might plausibly be invoked to explain (and promote) cooperation. Typically, only some subsets of these mechanisms are invoked, and the authors make the obvious point that it would be prudent to harness all seven in pursuit of 'green' objectives such as conservation within a framework of natural governance. Natural Governance seeks to "switch on" all seven triggers, or to identify and pick the right tools for the job (e.g., invoking adaptations for cooperation when there are mutual or inclusive fitness benefits from collective action). Curry et al.'s (submitted) review highlights how little attention has been given to many of these evolutionary understandings in formulating institutions and their cooperative modus operandi to tackle environmental problems (although St John et al. 2010 provide a practical example for conservation). Historically, researchers and policymakers have tended to focus on just one- - the Prisoner's Dilemma and its variants, presupposing a social dilemma with a high risk of exploitation.

Our super-cooperator approach, nudging humans to elicit ancient stimuli for cooperation which evolved in the setting of small groups raises the question of scale. In the case of cooperation, it is relatively easy to see congruence (at least) between the behavioural mechanisms that encourage cooperation within the societies of hunter gathering people and those of, say, interacting institutions or states, and to explore therein the dynamics of coalitions and dissent, and the cues which trigger or amplify them. While actors of vastly different scale, they are nevertheless subject to the same dynamics explored by game theory - a relatively small group of actors identifying best responses in strategic interaction. Scale itself is therefore not always an obstacle to logic. However, our approach is to go beyond the game theory to ask what evolved preferences and incentives will appeal to human beings? And what will make them (leaders, policy-makers, business people, and citizens alike) more willing to cooperate, over and above a raw cost-benefit analysis?

In this context, the third pillar of Natural Governanceculture - is also a critical strand of research. While behavioural sciences tell us what is universal among humans, evolutionary anthropology and cultural evolution document how these patterns vary among cultures - as different cultural adaptations to local adaptive problems. As with animals that often exhibit different social behaviour in different ecological settings, human behaviour has recurrent features, but these are fine-tuned to suit the prevailing environment (behavioural ecology). Other important cultural perspectives include the lens through which moral values, seemingly arising universally from natural selection, are expressed in particular domains of cooperation (Morality as Cooperation, Curry et al. 2017), the remarkable contrasts across cultures (Schwatrz 1996) (e.g., between Africa and India) in the reaction to a similar conservation issue (e.g., a lion kills a cow) (Meena et al. 2014), and contrasts which are even marked (between tolerance and vengefulness) between different tribal groups in Africa (Western et al. submitted 2018b). This adds considerable complexity to the simplicity of cooperative game theory, but allows us to adapt the models to the real world. 
112 / Macdonald et al.

In the context of conservation, humanity's commonalities with the rest of the Darwinian realm works both ways. Just as the human enterprise will benefit from understanding its nature, so will this realisation lead ineluctably to a nonanthropocentric ethical understanding of relationships with at least some other elements of the Darwinian realm (e.g., other mammals) that recognises a shared intrinsic value beyond the genus Homo (Vucetich et al. 2018). This ethical proposition has considerable practical implications for conservation (e.g., in an evaluation of how some arguments, such as the trophy hunting debate sparked by Cecil the Lion in 2015, should balance the protection of land for conservation against the consumptive use of a mammalian carnivore [Vucetich et al. 2018 submitted]).

\section{FROM TRAGEDY TO TRIUMPH: DEPLOYING OUR SCIENTIFIC TOOLKIT}

Perhaps lions can help again, this time Cecil the Lion, notorious victim of allegedly illegal bow-hunting about whom Macdonald et al. (2016) asked whether the Cecil Moment might become the Cecil Movement, a question phrased in the context of philosophical schools such as deontological versus consequentialist views (Macdonald et al. 2016), and for which lions are a metaphor for all biodiversity. Buhrmester et al. (2018), explored the attitudes of a sample of donors who had supported an appeal by the WildCRU following the Cecil moment. They demonstrated a link between the dysphoria that individuals felt on first hearing about the lion's killing and their subsequent "fusion" (a deeply felt connection) to both lion conservation and the research unit striving to deliver it. This sort of identity fusion - more typically studied in the context of, say, commitment among members of a combat group where loyalty to an idea overwhelms even the value of life (Brewer et al. 2017) - is thereby demonstrated, for the first time, to be available to those planning for conservation. How is this aspect of evolutionary psychology to be harnessed in uniting societal pressure (e.g., the Cecil Movement) for conservation, whether at the level of local constituencies or global opinion?

A similar question might be asked of Haidt's (2012) idea that awe of Nature (in this case a magnificent lion) activates the 'hive switch' that makes people 'less selfish'. Aided by the power of modern social media to mobilise and unite (Macdonald et al. 2012), perhaps the death of a beautiful lion was analogous to Martin Luther King's catalytic mobilisation of group action on the 1960s Civil Rights movement-the power of group action infusing people, parties, and ultimately a presidency (Milkis and Mileur 2002). Exactly which social unit is the most effective for mobilising change? While the particular answer for conservation may await study (Friedman [2017] argues generally that in the twenty first century, perhaps as in prehistory, it is the local community), it will surely necessitate an understanding of the individual decisions that lead to behaviour change (Moorhouse et al. 2017). Furthermore, other disciplines may have plenty to contribute to Natural Governance, a strong candidate being cognitive neuroscience, for example, where the discovery of mirror neurons offers a better understanding of how people resonate with particular ideas and suggests explicit triggers that can move people to act (Can and Macdonald 2018).

Of course, being mindful of Natural Governance is not the only solution for conservation. It will still need evidence gathered meticulously from studies on every scale from ecology and animal behaviour to geopolitics (Hodgetts et al. 2018 in press). It will also still need an holistic surge of transdisciplinarity (Macdonald 2019 in press), new financial mechanisms (Dickman et al. 2011), and hitherto unimagined clever links with development and poverty alleviation. Woven through these, however, we propose it will always be helpful to be mindful of human adaptations to give us the best chance of playing to our strengths.

\section{ACKNOWLEDGEMENTS}

We are grateful for insightful comments from Dawn Burnham, Emre Can, Oliver Curry, Peter Gluckman, Kim Jacobsen, Paul Johnson, John Vucetich, and Stuart West, and for Christopher O'Kane's considerable assistance with the manuscript. This work was generously supported by the Oxford Martin School.

\section{REFERENCES}

Agrawal, A. and M.C. Lemos. 2007. A greener revolution in the making: environmental governance in the $21^{\text {st }}$ century. Environment $49(5)$ : $36-45$.

Blackwell, P. 1990. Deterministic and stochastic-models of social-behavior based on the Resource Dispersion Hypothesis. Ima Journal of Mathematics Applied in Medicine and Biology 7(4): 261-279.

Brewer, J., M. Gelfand, J.C. Jackson, I.F. Macdonald, P.N. Peregrine, P.J. Richerson, P. Turchin, H. Whitehouse, and D.S. Wilson. 2017. Grand challenges for the study of cultural evolution. Nature Ecology \& Evolution 1(3)[0070].

Buhrmester, M.D., D., Burnham, D.D.P. Johnson, O.S. Curry, D.W. Macdonald, and H. Whitehouse. 2018. How moments become movements: shared outrage, group cohesion, and the lion that went viral. Frontiers in Ecology and Evolution 6(54). doi:10.3389/fevo.2018.00054.

Can, E.Ö. and D.W. Macdonald. 2018. Looking under the bonnet of conservation conflicts: can neuroscience help? Biodiversity Conservation 27(8): 2087-2091.

Carr, G.M. and D.W. Macdonald. 1986. The sociality of solitary foragers: a model based on resource dispersion. Animal Behaviour 34(5): 1540-1549.

Curry, O.S., D.A. Mullins, and H. Whitehouse. 2017. Is it good to cooperate? Testing the theory of morality-as-cooperation in 60 societies. Current Anthropology.

Curry, O.S., C. Hepburn, D. Hare, D. Johnson, M.D. Buhrmester, H. Whitehouse, and D.W. Macdonald. Submitted. The evolved environmentalist. Conservation Letters. In Review.

Cushman, S., N.B. Elliot, D. Bauer, K. Kesch, L. Bahaa-el-din, H. Bothwell, M. Flyman, G. Mtare, D.W. Macdonald, and A.J. Loveridge. 2018. Prioritizing, core areas, corridors and conflict hotspots for lion conservation in Southern Africa. PLoS ONE 13(7):e0196213. doi:10.1371.journal.pone.0196213.

Davies-Mostert, H.T., M.G. Mills, and D.W. Macdonald. 2009. A critical assessment of South Africa's managed metapopulation recovery strategy for African wild dogs and its value as a template for large carnivore conservation elsewhere. In: Reintroduction of top-order predators: Using Science to Restore One of the Drivers of Biodiversity (eds. Hayward, M.W. and M.J. Somers). Pp. 10-42. Oxford: WileyBlackwell. 
Dickman, A.J., E.A. Macdonald, and D.W. Macdonald. 2011. A review of financial instruments to pay for predator conservation and encourage human-carnivore coexistence. Proceedings of the National Academy of Sciences 108(34): 13937-13944.

Elliot, N.B., S.A. Cushman, D.W. Macdonald, and A.J. Loveridge 2014. The devil is in the dispersers: predictions of landscape connectivity change with demography. Journal of Applied Ecology 51(5): 1169-1178. doi:10.1111/1365-2664.12282.

Friedman, T. 2017. Thank you for being late: an optimist's guide to thriving in the age of accelerations. Farrar, Straus and Giroux.

Giphart, R. and M. van Vugt. 2018. Mismatch: how our stone age brain deceives us every day (and what we can do about it). London: Little Brown.

Gluckman, P. and M. Hanson. 2006. Mismatch: why our world no longer fits our bodies. Oxford University Press.

Haidt, J. 2012. The righteous mind: why good people are divided by politics and religion. Vintage. Allen Lane.

Hodgetts, T., M. Lewis, H. Bauer, D. Burnham, A. Dickman, E. Macdonald, D. Macdonald, and A. Troubhorst. 2018. Improving the role of global conservation treaties in addressing contemporary threats to lions. Biodiversity and Conservation 27(10): 2747-2765.

Hodgetts, T., E.A. Macdonald, A. Dickman, D. Burnham, A. Hinks, and D.W. Macdonald. In press. Conservation geopolitics: existing work, future directions. Conservation Biology.

Kahneman, D. 2011. Thinking, fast and slow. Macmillan.

Kruuk, H. 1975. Functional aspects of social hunting by carnivores. In: Function and evolution in behaviour (eds. Baerends, G.P., C. Beer, and A. Manning). Pp. 119-141. Oxford: Clarendon Press.

Kruuk, H. 1978. Spatial-organization and territorial behavior of European badger Meles meles. Journal of Zoology 184: 1-19.

Kruuk, H. and D.W. Macdonald. 1985. Group territories of carnivores: empires and enclaves. Behavioural ecology 521-536.

Macdonald D.W. 2019. In press. Mammal conservation - old problems, new perspectives, transdisciplinarity and the coming of age of conservation geopolitics. Annual Review of Environment and Resources.

Macdonald, D.W. and C. Newman. 2017. Mustelid sociology: the grass-roots of society. In: Biology and conservation of musteloids (eds. Macdonald, D.W., C. Newman, and L.A. Harrington). Oxford University Press.

Macdonald, D.W., P.J. Johnson, A.J. Loveridge, D. Burnham, and A.J. Dickman. 2016. Conservation or the moral high ground: siding with Bentham or Kant. Conservation Letters 9(4): 307-308.

Macdonald, D. W., D. Burnham, A.E. Hinks, and R. Wrangham. 2012. A problem shared is a problem reduced: seeking efficiency in the conservation of felids and primates. Folia Primatologica 83: 171-215.

Macdonald, D.W. and R.E. Feber. 2015. Wildlife conservation on farmland. Oxford University Press.

Macdonald, D.W. and D.P. Johnson. 2015. Patchwork planet: the resource dispersion hypothesis, society, and the ecology of life. Journal of Zoology 295(2): 75-107.

Macdonald, D.W., K.S. Jacobsen, D. Burnham, P.J. Johnson, and A.J. Loveridge. 2016. Cecil: a moment or a movement? Analysis of media coverage of the death of a lion, Panthera leo. Animals 6(5): 26.

Macdonald, D.W. 1983. The ecology of carnivore social behavior. Nature 301: 379-384.

Macdonald, E.A., A. Hinks, D.J. Weiss, A. Dickman, D. Burnham, C.J. Sandom, Y. Malhi, and D.W. Macdonald. 2017. Identifying ambassador species for conservation marketing. Global Ecology and Conservation 12: 204-214.

Meena, V., D.W. Macdonald, and R. Montgomery. 2014. Managing success: Asiatic lion conservation, interface problems and peoples' perceptions in the Gir Protected Area. Biological Conservation 174: $120-126$.

Milkis, S.M. and J.M. Mileur. 2002. The new deal and the triumph of liberalism. University of Massachusetts Press.

Miller, J.D., E.C. Scott, and S. Okamoto. 2006. Public acceptance of evolution. Science 313(5788): 765-766.

Moorhouse, T.P., M. Balaskas, N.C. D'Cruze, and D.W. Macdonald. 2017. Information could reduce consumer demand for exotic pets. Conservation Letters 10(3): 337-345.

Ostrom, E. 1990. Governing the commons. Cambridge: Cambridge University Press.

Schwartz, S. 1996. Value priorities and behavior: applying a theory of integrated value systems. In: The Ontario symposium: the psychology of values Volume 8 (eds. Seligman, U.C., J.M. Olson, and M.P. Zanna).

Stein, A. 1990. Why nations cooperate: circumstance and choice in international relations. Ithaca: Cornell University Press.

St John, F.A.V., G. Edwards-Jones, and J.P.G. Jones. 2010. Conservation and human behaviour: lessons from social psychology. Wildlife Research 37(8): 658-667.

Trouwborst, A., M. Lewis, D. Burnham, A. Dickman, A. Hinks, T. Hodgetts, E.A. Macdonald, and D.W. Macdonald. 2017. International law and lions (Panthera leo): understanding and improving the contribution of wildlife treaties to the conservation and sustainable use of an iconic carnivore. Nature Conservation 21: 83-128.

Vucetich, J.A., D. Burnham, E.A.Macdonald, J.T. Bruskotter, S. Marchini, A. Zimmermann, and D.W. Macdonald. 2018. Just conservation: what is it and should we pursue it? Biological Conservation 221: 23-33.

Vucetich, J.A., D. Burnham, P.J. Johnson, A.J. Loveridge, M.P. Nelson, J.T. Bruskotter, and D.W. Macdonald. Submitted. Some ethical considerations on trophy hunting and lion conservation.

Western, G., D.W. Macdonald, A. Loveridge, S. Russell, J. Kamanga, and T. Thronton. 2018a. Submitted. To move or not to move: changes in rangeland occupancy and livestock patterns within a lion landscape.

Western, G., D.W. Macdonald, A. Dickman, and A. Loveridge. 2018b. Submitted. Landscapes of tolerance: socio-economic and political factors affecting tolerance of lions in human-dominated landscape. 